\title{
Long-Term Survival under Arterial Chemoembolization and Sorafenib of a Patient with Hepatocellular Carcinoma and Tumor Atrial Thrombus: A Case Report and Literature Review
}

\author{
Andreas Mavroudis Evangelos Cholongitas \\ First Department of Internal Medicine, Laiko General Hospital, Medical School of National \\ and Kapodistrian University of Athens, Athens, Greece
}

\section{Keywords}

Hepatocellular carcinoma - Right atrium tumor thrombus · Sorafenib ·

Transarterial chemoembolization

\begin{abstract}
Hepatocellular carcinoma (HCC) is considered to be the fourth most frequent cause of cancerassociated death globally. HCC might be associated, especially in advanced stages, with the formation of tumor thrombus (TT), which can be located in the portal vein, as well as in hepatic and/or inferior vena cava (IVC) veins. Nevertheless, the extension of TT to the right atrium (RA) is infrequent with an unfavorable prognosis. We present a rare case of a male patient with HCC and IVC TT extending to the RA. The atrial thrombus was the first manifestation of HCC diagnosed by cardiac ultrasound. So far, the patient has undergone 4 courses of transarterial chemoembolization in combination with systemic therapy with sorafenib, and under this therapeutic approach long-term survival has been achieved.

\section{Introduction}

Hepatocellular carcinoma (HCC) is the fourth leading cause of cancer-associated death globally. On a global basis, it accounts for approximately 800,000 deaths annually [1]. The formation of tumor thrombus (TT) in advanced HCC is common, and its presence usually involves the portal vein [2]. However, the presence of TT in the inferior vena cava (IVC) and its extension to the right atrium (RA) are rare, approximately 3.8 and $2 \%$, respectively, and 
associated with a poor prognosis, with a median survival time of 2-5 months for untreated patients [3]. Herein, we describe a patient with HCC and TT in the IVC and RA as initial diagnosis with long-term survival under arterial chemoembolization (TACE) and systemic therapy.

\section{Case Report}

A 73-year-old male patient presented at the emergency unit with progressively worsening dyspnea during the last 15 days. The patient had been assessed by a cardiologist, and the presence of a solid mass thrombus in the RA had been revealed in the cardiac ultrasound. The patient was admitted to our department for further evaluation. His medical history included type II diabetes mellitus under a vildagliptin - a dipeptidyl peptidase 4 inhibitor - and metformin combination regimen and daily alcohol consumption (2 glasses of wine daily during the last 30 years). The patient's body weight and height were $85 \mathrm{~kg}$ and $180 \mathrm{~cm}$, respectively (body mass index 26.2). The clinical examination revealed a mild tenderness upon palpation of the right upper quadrant of the abdomen. Liver function tests were within normal ranges: total bilirubin $(0.57$ $\mathrm{mg} / \mathrm{dL}$, upper limits of normal [ULN]: $1.2 \mathrm{mg} / \mathrm{dL})$, direct bilirubin (0.29 mg/dL, ULN: $0.30 \mathrm{mg} / \mathrm{dL}$ ), aspartate aminotransferase (18 U/L, ULN: $40 \mathrm{U} / \mathrm{L})$, alanine aminotransferase (12 U/L, ULN: $41 \mathrm{U} / \mathrm{L})$, alkaline phosphatase (76 U/L, ULN: $129 \mathrm{U} / \mathrm{L}$ ), $\gamma$-glutamyltransferase (48 U/L, ULN: $61 \mathrm{U} / \mathrm{L}$ ), total protein (7.6 g/dL, ULN: $7.9 \mathrm{~g} / \mathrm{dL}$ ), albumin ( $4.7 \mathrm{~g} / \mathrm{dL}, \mathrm{ULN}: 5.0 \mathrm{~g} / \mathrm{dL})$ and international normalized ratio (1.1) were within the normal range. Serological markers for hepatitis $\mathrm{B}$ and $\mathrm{C}$ virus and human immunodeficiency virus were negative, as well as antinuclear antibodies, anti-smooth muscle antibodies and antimitochondrial antibodies. The transthoracic echocardiogram confirmed the presence of a solid formation with dimensions of $5 \times 3 \mathrm{~cm}$ in the RA. The shear wave elastography revealed mild liver fibrosis (Metavir score F2). The computer scan tomography (CT scan) of the chest and abdomen revealed the presence of a liver mass with radiological findings compatible with HCC, as well as the presence of a neoplastic thrombus in the IVC with extension to the RA, but without evidence of lung metastases or pulmonary embolism. The patient underwent a liver biopsy which was consistent with moderately differentiated HCC. Based on the Barcelona Clinic Liver Cancer (BCLC) staging system, our patient was BCLC stage C [3].

In our case, due to the patient's preference and after surgical consultation, surgery was not performed. However, the patient underwent 4 sessions of TACE (Fig. 1a-c), while low-molecular-weight heparin (enoxaparin sodium: 6,000 IU $\times 2$ /day) and sorafenib at a reduced dosage (400 $\mathrm{mg} /$ day) were given. With this regimen he is in a stable health condition, and during a 16-month follow-up with CT scan the dimensions of HCC and RA TT remain unchanged (Fig. 1). Except for a mild increase in total bilirubin (3.33 mg/dL), alkaline phosphatase (311 U/L) and $\gamma$-glutamyltransferase (225 U/L) after the first session of TACE, liver function parameters of the patient during TACE sessions and periodic screening tests remained within normal ranges during the aforementioned period.

\section{Discussion}

HCC with TT in the IVC or RA is a rare entity and may be related with a number of complications (heart failure, pulmonary embolism, lung metastases and death predominantly due to pulmonary embolism and occlusion of the tricuspid valve) and consequently with poor prognosis [2-5]. Budd-Chiari syndrome and symptoms of acute right heart failure and pulmonary embolism are some of the clinical manifestations of HCC with TT in the RA [2]. Our patient had dyspnea, but no findings compatible with pulmonary embolism or lung metastases were found. In fact, atrial thrombus was the first manifestation of HCC as it was found in cardiac ultrasound and confirmed in the CT scan. To our knowledge there are also 3 case reports of patients who presented with dyspnea as the first manifestation of HCC with RA TT. In these cases, the diagnosis of TT in the RA was based on CT/MRI or cardiac ultrasound, the patients underwent surgery or TACE, but their survival was very poor (up to 6 months) [6-8]. In our patient, the diagnosis of TT in the RA was made by cardiac ultrasound and established by CT, while under combination of TACE with sorafenib long-term survival was achieved. 


\begin{tabular}{|c|c|c|}
\hline \multirow[b]{2}{*}{$\begin{array}{l}\text { Gastrointestinal } \\
\text { Tumors }\end{array}$} & \multicolumn{2}{|c|}{ Gastrointest Tumors 2020;7:156-161 } \\
\hline & DOI: $10.1159 / 000509186$ & $\begin{array}{l}\text { (c) } 2020 \text { The Author(s). Published by S. Karger AG, Basel } \\
\text { www.karger.com/gat }\end{array}$ \\
\hline
\end{tabular}
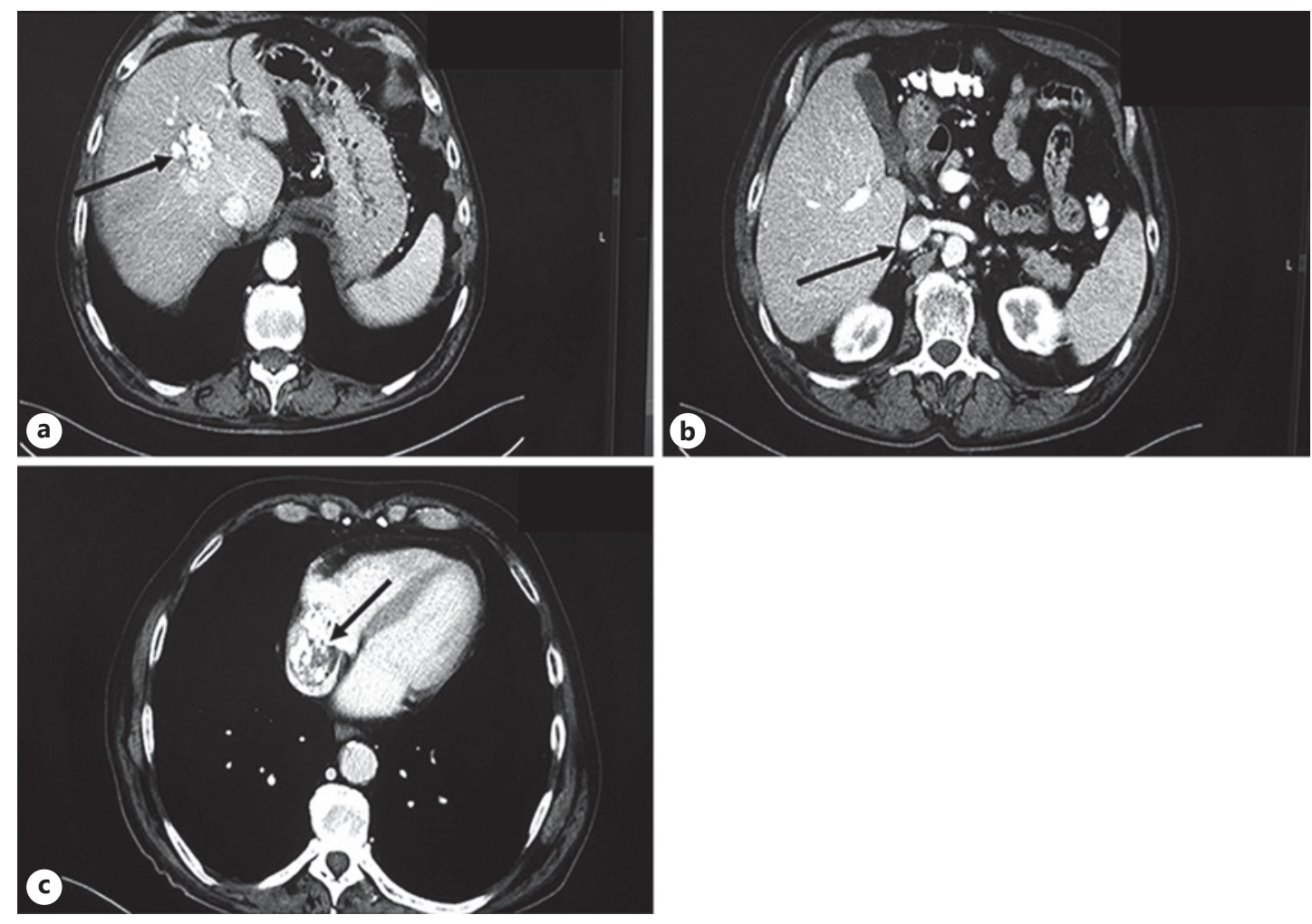

Fig. 1. Hepatocellular carcinoma and embolic particles after the last transarterial chemoembolization in the right hepatic lobe (a) and tumor thrombus in the inferior vena cava (b) and right atrium (c), respectively (black arrows).

According to its anatomic location, there are 3 types of TT: the inferior hepatic type, where the TT is in the IVC and below the diaphragm (type I), the superior hepatic type, where the TT is above the diaphragm but does not invade the RA (type II), and the intracardiac type with the extension of TT in the RA (type III) [2, 3, 5]. Our patient had type III TT. Based on the BCLC staging system, patients with type III TT are classified as BCLC stage C due to the extrahepatic spread of the HCC. Officially these patients are eligible only for systemic therapy, such as sorafenib $[2,9]$, but in the literature (Table 1), hepatectomy and thrombectomy under cardiopulmonary bypass have been suggested as treatment modality linked with better prognosis (survival range: 3-30.8 months), compared to nonsurgical therapy [2, 3] (Table 1). However, the procedure is challenging, demands a multidisciplinary team and a high operative risk also exists $[3,4]$. Hence, this treatment approach is implemented in patients with a general good health condition and in those with symptoms of congestive heart failure. However, the majority of patients with HCC have poor performance status and they are often not considered as surgical candidates [10]. Therefore, other treatment options including TACE, percutaneous microwave ablation, radiation therapy and systemic therapy with multikinase inhibitors, such as sorafenib, or immune checkpoint inhibitors, such as nivolumab, have also been used for these patients (Table 1).

Based on the literature data (Table 1), the survival time for patients treated with sorafenib ranged from 2 to 17 months [10-13]. For patients treated with TACE the median survival time was 4.5 months, while for those who received no treatment it was $2-5$ months $[3,14]$. In the literature we found no study with a combination of TACE and systemic therapy for HCC with the presence of TT in the RA. 


\section{Gastrointestinal Tumors}

\begin{tabular}{l|l}
\hline DOI: $10.1159 / 000509186$ & $\begin{array}{l}\text { C) 2020 The Author(s). Published by S. Karger AG, Basel } \\
\text { www.karger.com/gat }\end{array}$
\end{tabular}

Mavroudis and Cholongitas: Hepatocellular Carcinoma and Tumor Atrial Thrombus

Table 1. Overview of case studies on the treatment and survival of patients with hepatocellular carcinoma and tumor atrial thrombus $[2,4,7,10,13-35]$

\begin{tabular}{|c|c|c|c|c|}
\hline Study & Study type & Cases & Therapeutic approach & $\begin{array}{l}\text { Outcome, } \\
\text { survival in months }\end{array}$ \\
\hline Zhan et al. [10] & Case series & 3 & $\begin{array}{l}\text { 1st patient: sorafenib } \\
\text { 2nd patient: chemotherapy and then sorafenib } \\
\text { 3rd patient: nivolumab }\end{array}$ & $\begin{array}{l}\text { 1st patient: } 17 \\
\text { 2nd patient: } 9 \\
\text { 3rd patient: } 10 / \text { alive }\end{array}$ \\
\hline Wang et al. [14] & $\begin{array}{l}\text { Retrospective cohort } \\
\text { study }\end{array}$ & 56 & $\begin{array}{l}\text { (a) Resection of tumor and thrombus ( } 25 \text { patients) } \\
\text { (b) TACE ( } 20 \text { patients) } \\
\text { (c) Symptomatic treatment ( } 11 \text { patients) }\end{array}$ & $\begin{array}{l}\text { Median: } \\
\text { (a) } 19 \\
\text { (b) } 4.5 \\
\text { (c) } 5\end{array}$ \\
\hline Wakayama et al. [15] & Case series & 6 & Resection of tumor and thrombus under $\mathrm{CPB}$ & Mean: 13.9 \\
\hline Sengodan et al. [13] & Case report & 1 & Sorafenib & 2 \\
\hline Pesi et al. [16] & Case series & 3 & Resection of tumor and thrombus under $\mathrm{CPB}$ & Median: 3 \\
\hline Duan et al. [17] & $\begin{array}{l}\text { Retrospective case } \\
\text { series }\end{array}$ & 11 & $\begin{array}{l}\text { TACE and EBRT ( } 2 \text { patients also received systemic } \\
\text { chemotherapy and } 5 \text { patients sorafenib) }\end{array}$ & Median: 21 \\
\hline Li et al. [18] & Case report & 1 & Resection of tumor and thrombus under THVE without CPB & 6 \\
\hline Luo et al. [19] & Case report & 1 & Thrombectomy under CPB, then TACE and MWA & 6 \\
\hline Ohta et al. [4] & Case report & 1 & Resection of tumor and thrombus under CPB & 10/alive \\
\hline Li et al. [20] & Case report & 1 & TACE and MWA & 16/alive \\
\hline Lubezky et al. [21] & Case report & 1 & Resection of tumor and thrombus under venovenous bypass & 13 \\
\hline Sabzi et al. [22] & Case report & 1 & $\begin{array}{l}\text { Thrombectomy, then resection of tumor } \\
\text { and adjuvant chemotherapy }\end{array}$ & Not mentioned \\
\hline Chen et al. [23] & Case report & 1 & No treatment modality & 1.4 \\
\hline Ariizumi et al. [24] & Case report & 1 & Resection of tumor and thrombus under $\mathrm{CPB}$ & 14/alive \\
\hline Zhu et al. [25] & $\begin{array}{l}\text { Retrospective case } \\
\text { series study }\end{array}$ & 18 & TACE & Mean: 15.2 \\
\hline Ninomiya et al. [26] & Case report & 1 & Resection of thrombus & 6/alive \\
\hline Otsuru et al. [27] & Case report & 1 & $\begin{array}{l}\text { Resection of tumor and thrombus, then hepatic arterial } \\
\text { infusion chemotherapy and sorafenib }\end{array}$ & Not mentioned \\
\hline Takechi et al. [28] & Case report & 1 & TACE & 25/alive \\
\hline Vishnevsky et al. [29] & Case report & 1 & Resection of tumor and thrombus & Not mentioned \\
\hline Chandra et al. [30] & Case report & 1 & Sorafenib & Not mentioned \\
\hline Vicente et al. [31] & Case report & 1 & Resection of tumor and thrombus under THVE without CPB & 24/alive \\
\hline Hyuga et al. [32] & Case report & 1 & Resection of tumor and thrombus, FAIT and sorafenib & 35/alive \\
\hline Kawakami et al. [33] & Case report & 1 & Anticoagulation therapy & 5 \\
\hline Numan et al. [2] & Case report & 1 & Sorafenib & 2 \\
\hline $\begin{array}{l}\text { Sempokuya and } \\
\text { Bolger [34] }\end{array}$ & Case report & 1 & No treatment modality & Not mentioned \\
\hline Lou et al. [35] & $\begin{array}{l}\text { Retrospective case } \\
\text { series study }\end{array}$ & 18 & Hypofractionated radiotherapy & Median: 11.6 \\
\hline Hayashida et al. [7] & Case report & 1 & Resection of thrombus under CPB and TACE postoperatively & 6 \\
\hline
\end{tabular}

In the section of survival, the term "alive" refers to those patients who were alive since the publication time of the original article. TACE, transarterial chemoembolization; CPB, cardiopulmonary bypass; EBRT, external beam radiation therapy; THVE, total hepatic vascular exclusion; MWA, microwave ablation; FAIT, fluorouracil arterial infusion and interferon therapy. 
In conclusion, long-term survival in patients with HCC and RA TT has been mainly managed either by resection of tumor and TT alone $[14,15,21,24,29]$ or, when surgery was not feasible, with other therapeutic approaches (sorafenib, TACE, systemic chemotherapy, ablation) [10, 25, 28]. However, long-term survival is also possible when nonsurgical therapeutic options are combined, as in our patient. In fact, our patient was the first with long-term survival and good quality of life without complications or adverse events under TACE plus sorafenib combination. Studies on adjuvant and neoadjuvant therapies are currently in progress, and their results could modify the therapeutic strategies for recurrent and metastatic HCC and finally improve patient survival and prognosis $[3,11,33,36]$.

\section{Statement of Ethics}

The study complies with the World Medical Association Declaration of Helsinki. The patient has given written informed consent to publish the case (including publication of images).

\section{Disclosure Statement}

The authors have no conflicts of interest to declare.

\section{Funding Sources}

There are no funding sources to declare.

\section{Author Contributions}

A.M. and E.C.: conception and design. All the authors: analysis and interpretation of the data. E.C.: drafting of the article. E.C.: critical revision of the article for important intellectual content. All the authors: final approval of the paper.

\section{References}

1 Akinyemiju T, Abera S, Ahmed M, Alam N, Alemayohu MA, Allen C, et al.; Global Burden of Disease Liver Cancer Collaboration. The Burden of Primary Liver Cancer and Underlying Etiologies From 1990 to 2015 at the Global, Regional, and National Level: Results From the Global Burden of Disease Study 2015. JAMA Oncol. 2017 Dec; 3(12): 1683-91.

2 Numan L, Asif S, Abughanimeh OK. Hepatocellular Carcinoma with Tumor Thrombus Extending from the Portal Vein to the Right Atrium. Cureus. 2019 May; 11(5):e4689.

3 Sakamoto K, Nagano H. Outcomes of surgery for hepatocellular carcinoma with tumor thrombus in the inferior vena cava or right atrium. Surg Today. 2018 Sep; 48(9): 819-24.

4 Ohta M, Nakanishi C, Kawagishi N, Hara Y, Maida K, Kashiwadate T, et al. Surgical resection of recurrent extrahepatic hepatocellular carcinoma with tumor thrombus extending into the right atrium under cardiopulmonary bypass: a case report and review of the literature. Surg Case Rep. 2016 Dec; 2(1): 110.

5 Zhang Y, Wu Z, Wang K, Han S, Li C, Li X. Long-term survival after anterior approach right hepatectomy combined with inferior vena cava thrombectomy using trans-diaphragmatic intrapericardial inferior vena cava occlusion: a case report and review of the literature. BMC Surg. 2019 Aug; 19(1): 122.

6 Mikhno L, Afzal A, Sonawala T, Palta S, Worku B, Gulkarov I. Hepatocellular Carcinoma Presenting as an Incidental Right Atrial Mass. J Card Surg. 2016 Jan; 31(1): 60.

7 Hayashida K, Okumura S, Kawase T. Right atrial obstruction due to cardiac extension of hepatocellular carcinoma. Asian Cardiovasc Thorac Ann. 2014 May; 22(4): 465-8.

8 Alraies MC, Khan UA, Alraiyes AH, Auron M. Right atrium tumor thrombus. QJM. 2013 Jul; 106(7): 679-80.

9 Forner A, Reig M, Bruix J. Hepatocellular carcinoma. Lancet. 2018 Mar; 391(10127): 1301-14.

10 Zhan T, Sollors J, Steinebrunner N, Schlitt HJ, Stroszczynski C, Weiss KH, et al. Pharmacological treatment of hepatocellular carcinoma with cavoatrial tumor thrombus - case series and literature review. Z Gastroenterol. 2019 Apr; 57(4): 501-7. 
11 Llovet JM, Ricci S, Mazzaferro V, Hilgard P, Gane E, Blanc JF, et al.; SHARP Investigators Study Group. Sorafenib in advanced hepatocellular carcinoma. N Engl J Med. 2008 Jul; 359(4): 378-90.

12 Cheng AL, Kang YK, Chen Z, Tsao CJ, Qin S, Kim JS, et al. Efficacy and safety of sorafenib in patients in the AsiaPacific region with advanced hepatocellular carcinoma: a phase III randomised, double-blind, placebo-controlled trial. Lancet Oncol. 2009 Jan; 10(1): 25-34.

13 Sengodan P, Grewal H, Gandhi S. Invasive hepatocellular carcinoma with recurrent pulmonary embolism: use of AngioVac cannula thrombectomy device for mechanical aspiration. J Invasive Cardiol. 2014 Jul; 26(7):E100-3.

14 Wang Y, Yuan L, Ge RL, Sun Y, Wei G. Survival benefit of surgical treatment for hepatocellular carcinoma with inferior vena cava/right atrium tumor thrombus: results of a retrospective cohort study. Ann Surg Oncol. 2013 Mar; 20(3): 914-22.

15 Wakayama K, Kamiyama T, Yokoo H, Kakisaka T, Kamachi H, Tsuruga Y, et al. Surgical management of hepatocellular carcinoma with tumor thrombi in the inferior vena cava or right atrium. World J Surg Oncol. 2013 Oct; 11(1): 259.

16 Pesi B, Giudici F, Moraldi L, Montesi G, Romagnoli S, Pinelli F, et al. Hepatocellular carcinoma on cirrhosis complicated with tumoral thrombi extended to the right atrium: results in three cases treated with major hepatectomy and thrombectomy under hypothermic cardiocirculatory arrest and literature review. World J Surg Oncol. 2016 Mar; 14(1): 83.

17 Duan F, Yu W, Wang Y, Liu FY, Song P, Wang ZJ, et al. Trans-arterial chemoembolization and external beam radiation therapy for treatment of hepatocellular carcinoma with a tumor thrombus in the inferior vena cava and right atrium. Cancer Imaging. 2015 May; 15(1): 7.

18 Li AJ, Yuan H, Yin L, Che Q, Lang XL, Wu MC. Cavoatrial thrombectomy in hepatocellular carcinoma with tumor thrombus in the vena cava and atrium without the use of cardiopulmonary bypass. Ann Vasc Surg. 2014 Aug. 28(6): 1565.e5-8.

19 Luo X, Zhang B, Dong S, Zhang B, Chen X. Hepatocellular Carcinoma With Tumor Thrombus Occupying the Right Atrium and Portal Vein: A Case Report and Literature Review. Medicine (Baltimore). 2015 Aug; 94(34):e1049.

20 Li W, Wang Y, Gao W, Zheng J. HCC with tumor thrombus entering the right atrium and inferior vena cava treated by percutaneous ablation. BMC Surg. 2017 Feb; 17(1): 21.

21 Lubezky N, Nachmany I, Goykhman Y, Ben-Gal Y, Menachem Y, Geva R, et al. Surgical Treatment of Hepatocellular Carcinoma with a Tumor Thrombus Extending into the Right Atrium. Isr Med Assoc J. 2018 Sep; 20(9): 590-1.

22 Sabzi F, Heidari A, Faraji R. Isolated Right Atrial Mass in a Candidate of Coronary Bypass Grafting. Acta Med Iran. 2017 Nov; 55(11): 722-5.

23 Chen M, Huang X, Yang Q. Hepatocellular carcinoma with inferior vena cava and right atrial tumor thrombus: A case report. Echocardiography. 2019 Nov; 36(11): 2110-3.

24 Ariizumi SI, Kikuchi C, Tokitou F, Yamashita S, Kotera Y, Omori A, et al. Cavo-atrial thrombectomy prior to hepatectomy for hepatocellular carcinoma with tumor thrombus in the right atrium: a case report. Surg Case Rep. 2019 Apr; 5(1): 57.

25 Zhu L, Yang R, Zhu X. Transcatheter arterial chemoembolization experience for advanced hepatocellular carcinoma with right atrial tumor thrombus. J Cancer Res Ther. 2019; 15(2): 305-11.

26 Ninomiya R, Nakazawa A, Mitsui T, Miyata Y, Komagome M, Ozawa F, et al. [Resection for the Recurrence of Hepatocellular Carcinoma in the Inferior Vena Cava and Right Atrium under Deep Hypothermic Circulatory Arrest]. Gan To Kagaku Ryoho. 2018 Feb; 45(2): 390-2.

27 Otsuru T, Kobayashi S, Eguchi H, Wada H, Iwagami Y, Yamada D, et al. [A Case of Hepatocellular Carcinoma with Right Atrium Tumor Thrombus and Multiple Intrahepatic Metastases That Remarkably Responded to Combination Therapy Including Surgery]. Gan To Kagaku Ryoho. 2018 Jan; 45(1): 187-9.

28 Takechi K, Hori S, Yamashiro K, Yuki T, Hori A. [A Case of Successful Drug-Eluting Microsphere Transcatheter Arterial Embolization for Hepatocellular Carcinoma with Associated Tumor Thrombus in the Inferior Vena Cava and Right Atrium]. Gan To Kagaku Ryoho. 2016 Nov; 43(11): 1385-8.

29 Vishnevsky VA, Korostelev AN, Efanov MG, Subbotin VV, Iliyn SA, Sitnikov AV, et al. [Liver resection in patient with hcc and right atrium thrombosis]. Angiol Sosud Khir. 2015; 21(3): 159-65.

30 Chandra P, Shah S, Purandare N, Agrawal A, Rangarajan V. Hepatocellular carcinoma with intra-atrial tumor extension identified on $99 \mathrm{mTc}$-labeled macroaggregated albumin single photon emission computed tomography/computed tomography. Indian J Nucl Med. 2016 Oct-Dec; 31(4): 311-2.

31 Vicente E, Quijano Y, Ielpo B, De Luca GM, Prestera A, Duran H, et al. Cavoatrial thrombectomy without the use of cardiopulmonary bypass for abdominal tumors. Our experience and state of the art. Ann Vasc Surg. 2015 Jul; 29(5): 1020.e1-5.

32 Hyuga S, Tomokuni A, Tomimaru Y, Wada H, Hama N, Kawamoto K, et al. [Long-term survival in a case of advanced hepatocellular carcinoma with tumor thrombus in the portal vein and the right atrium (vp4,vv3) treated successfully with multidisciplinary therapies]. Gan To Kagaku Ryoho. 2014 Nov; 41(12): 2130-2.

33 Kawakami M, Koda M, Mandai M, Hosho K, Murawaki Y, Oda W, et al. Isolated metastases of hepatocellular carcinoma in the right atrium: case report and review of the literature. Oncol Lett. 2013 May; 5(5): 1505-8.

34 Sempokuya T, Bolger DT Jr. Right Atrium Invasion of Tumor Thrombus from Hepatocellular Carcinoma Incidentally Found on Transthoracic Echocardiogram. Hawaii J Med Public Health. 2018 Jun; 77(6): 131-4.

35 Lou J, Li Y, Liang K, Guo Y, Song C, Chen L, et al. Hypofractionated radiotherapy as a salvage treatment for recurrent hepatocellular carcinoma with inferior vena cava/right atrium tumor thrombus: a multi-center analysis. BMC Cancer. 2019 Jul; 19(1): 668.

36 Tella SH, Mahipal A, Kommalapati A, Jin Z. Evaluating the Safety and Efficacy of Nivolumab in Patients with Advanced Hepatocellular Carcinoma: evidence to Date. OncoTargets Ther. 2019 Nov; 12: 10335-42. 